\title{
An MS-CASPT2 Study of the Photodecomposition of 4- Methoxyphenyl Azide. Role of Internal Conversion and Intersystem Crossing
}

Daniel Aranda, Francisco J. Avila, Isabel López-Tocón, Juan F. Arenas, Juan C. Otero, Juan Soto

\author{
Department of Physical Chemistry, Faculty of Science, University of Málaga \\ E-mail: aranda@uma.es
}

Aryl azides photochemistry is strongly dependent on the substituent relative position, as has been studied by time resolved resonant Raman $\left(\mathrm{TR}^{3}\right)$ spectroscopy for 4-methoxyphenyl azide and its isomer 3-methoxyphenyl azide. [1,2] When irradiated at $266 \mathrm{~nm}$, the former results in 4,4'dimethoxyazobenzene whereas the latter forms 1,2-didehydroazepine. It is proposed that the key step of the reactions is the formation of a nitrene derivative. Recently, it has been proposed by us that nitrenes might have a relevant role in the Surface-Enhanced Raman Scattering (SERS) of $p$ aminothiophenol, [3] however, the molecular mechanism is not well known in neither of these cases. Therefore, we studied the photodecomposition of 4methoxyphenyl azide [4] using multiconfigurational self-consistent field methods (MC-SCF) with the CAS-SCF and MS-CASPT2 approximations and calculated the resonant Raman spectra of the relevant species using a multi-state version of Albrecht's vibronic theory. The results propose that the reaction follows a two steps sequence after irradiation at $266 \mathrm{~nm}$ : an intersystem crossing $2^{1} \mathrm{~A}^{\prime} / 2^{3} \mathrm{~A}^{\prime \prime}$ which decays through a $2^{1} \mathrm{~A}^{\prime} / 2^{1} \mathrm{~A}^{\prime \prime}$ conical intersection producing molecular nitrogen and triplet 4-methoxyphenyl nitrene in its ground state.

\section{References}

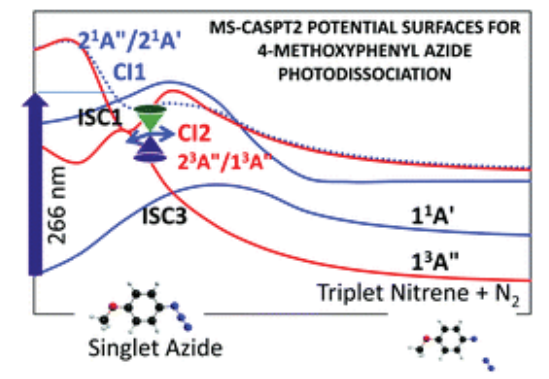

[1] S. Y. Ong, P. Y. Chang, P. Zhu, K. H. Leung And D. L. Philipps, J. Phys. Chem. A, 2003, 107, 3858-3865.

[2] W. M. KWOK, P. Y. ChAN AND D. L. Phillips, J. PhYS. Chem. A, 2005, 109, 2394-2400.

[3] M. R. Lopez-RamiRez, D. Aranda Ruiz, F. J. Avila Ferrer, S. P. Centeno, J. F. Arenas, J. C. OTERO AND J. SOTO, J. PHYS. CHEM. C, 2016, 120, 19322-19328.

[4] D. Aranda, F. J. Avila, I. López-Tocón, J. F. Arenas, J. C. Otero and J. Soto, Phys. Chem. CHEM. PHYS., 2018, 20, 7764-7771. 